\title{
KNOWLEDGE AND PRACTICES AMONG MOTHERS AND CAREGIVERS REGARDING NEONATAL WARMTH CARE AND TO DETECT HYPOTHERMIA WITH HEALTH EDUCATION USING THERMOSPOT IN POSTNATAL WARD AT GOVERNMENT GENERAL HOSPITAL, KAKINADA
}

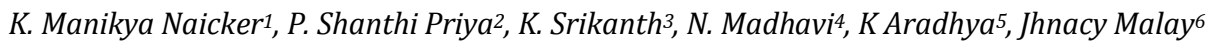

${ }_{1}^{1}$ Designated Associate Professor, Department of Paediatrics, Rangaraya Medical College, Kakinada, Andhra Pradesh, India.

2Junior Resident, Department of Paediatrics, Rangaraya Medical College, Kakinada, Andhra Pradesh, India.

3Junior Resident, Department of Paediatrics, Rangaraya Medical College, Kakinada, Andhra Pradesh, India.

${ }^{4}$ Professor, Department of Paediatrics, Rangaraya Medical College, Kakinada, Andhra Pradesh, India.

5Junior Resident, Department of Paediatrics, Rangaraya Medical College, Kakinada, Andhra Pradesh, India.

${ }^{6}$ Assistant Professor, Department of Paediatrics, Rangaraya Medical College, Kakinada, Andhra Pradesh, India.

\begin{abstract}
BACKGROUND
ABSTRACT

Neonatal hypothermia is increasingly recognized as a major cause of neonatal morbidity and mortality. Warmth care is an essential component of newborn interventions to reduce neonatal mortality. The present study deals with the knowledge, attitude and neonatal warmth care practices among postnatal mothers/care givers in the postnatal ward and aims to assess the level of understanding, acceptance and implementation of warmth care practices among mothers/care givers. As ThermoSpot is proven to be useful in detecting hypothermia in newborn babies, mothers were taught to detect hypothermia and take necessary steps by observing the colour changes of ThermoSpot. We wanted to assess the knowledge, attitude and neonatal warmth care practices among postnatal mothers/care givers in the postnatal ward. We also wanted to educate the mothers to detect hypothermia in the newborn with a simple tool like ThermoSpot and to educate them regarding correct neonatal warmth care practices.
\end{abstract}

\section{METHODS}

This is a hospital based interventional study, conducted among 108 post-natal mothers for a period of 6 months. Sociodemographic details of mothers were collected in a proforma. Neonatal warmth care practices followed by mothers were noted. ThermoSpot was applied to all 108 babies and any change in the colour of ThermoSpot was recorded on day 1, at 48 hours and at 72 hours. All mothers were educated about interpretation of change in colour of the ThermoSpot in detecting hypothermia or fever in the newborn baby. Data was analysed using Microsoft Excel and SPSS (Version 20) software.

\section{RESULTS}

Out of 108 mothers, majority were in 20-24 years age group. Literacy and multiparity of the mothers were found to have statistical significance $(p<0.05)$ regarding the knowledge of drying the baby and wrapping with warm clothes. Mothers of nuclear family, higher socioeconomic status, higher parity, and who had normal vaginal delivery, had shown higher knowledge about skin to skin contact which was statistically significant $(\mathrm{p}<0.05)$. Knowledge about rooming in had shown statistical significance among educated mothers, mothers belonging to higher socioeconomic status, higher parity and who had normal vaginal delivery ( $p$ < 0.05). There was no statistical significance between knowledge of mothers about timing of new-born's first bath and demographic profile of mothers. Out of 108 mothers, $86(79.6 \%)$ had knowledge to initiate breast feeds immediately after delivery where as $20.4 \%$ of mothers thought that breast feeds can be fed only when baby cries. Out of 648 ThermoSpot readings, 4 mothers reported PALE GREEN once, and one mother reported RED colour once. Data was analysed using Microsoft Excel and SPSS (Version 20) software.

\section{CONCLUSIONS}

In the present study, lack of maternal education on essential newborn care during antenatal (5\%) and postnatal periods (13\%) by health personnel was found to be one of the important factors contributing to poor knowledge and implementation of essential newborn warmth care practices. As ThermoSpot is not costly (Rs. 7 per device) and established to be useful to detect hypothermia, it can be incorporated in the neonatal kit supplied to health workers.

HOW TO CITE THIS ARTICLE: Naicker KM, Priya PS, Srikanth K, et al. Knowledge And Practices Among Mothers And Caregivers Regarding Neonatal Warmth Care And To Detect Hypothermia With Health Education Using Thermospot In Postnatal Ward At Government General Hospital, Kakinada. J. Evolution Med. Dent. Sci. 2019;8(16):1336-1341, DOI: 10.14260/jemds/2019/297

'Financial or Other Competing Interest': None.

Submission 26-02-2019, Peer Review 09-04-2019,

Acceptance 16-04-2019, Published 22-04-2019.

Corresponding Author:

Dr. N. Madhavi,

D. No. 2-46/25/2,

Rajyalakshmi Nagar, Opp. Pragathi Junior College,

Godarigunta Road, Kakinada-533003,

Andhra Pradesh, India.

E-mail: madhaviped205@gmail.com

DOI: $10.14260 /$ jemds $/ 2019 / 297$

\section{BACKGROUND}

Neonatal deaths account for $56 \%$ of under- 5 deaths in India which is much higher than the global average of $44 \%{ }^{1}$. The current neonatal mortality rate in India is 25 per 1000 live births $^{2}$ in 2016. The direct causes of neonatal deaths worldwide are prematurity (29\%), severe infections (29\%), birth asphyxia (23\%) and congenital malformations (8\%). Neonatal hypothermia is increasingly recognized as a major cause of neonatal morbidity and mortality. Despite availability of global guidelines and recommendations for neonatal care, there are major gaps in our understanding of the burden, risk factors, and consequences of neonatal 
hypothermia. Before birth, baby is warm, well insulated in the aqueous uterine environment. Immediately after birth, newborn's temperature can drop at a rate of $0.1^{\circ} \mathrm{C}$ and $0.3^{\circ} \mathrm{C}$ for core and skin temperature respectively due to which newborn baby is at maximum risk of hypothermia. WHO recommends warm chain and skin to skin care as most essential components of providing warmth care to newborn babies. As risks and consequences of hypothermia are considerable, research to further elucidate the impact of specific thermal care interventions on hypothermia risk and the overall contribution of these practices in improving neonatal survival is required.

The aim of present study was to assess the knowledge, attitude and neonatal warmth care practices among postnatal mothers/care givers in the postnatal ward and to assess the level of understanding, acceptance and implementation of warmth care practices among mothers/care givers during first three days of life using a ThermoSpot.

\section{METHODS}

The present study was a hospital based interventional study, conducted among post-natal mothers for a period of 6 months from Jan 2017 to June 2017 in Government General Hospital, Kakinada. Postnatal mothers whose neonates died or admitted in NICU, critically sick and mentally ill mothers, postnatal mothers of babies with major congenital anomalies and mothers/caregivers who are not willing to participate were excluded from this study.

The present study was conducted after taking approval by institutional ethical committee. 108 post-natal mothers/care givers were included in the study after taking written consent. One hour after birth, axilla of the newborn was cleaned with sterile cotton swab, dry and clean digital thermometer was kept in the axilla till the beep sound was heard. The temperature was recorded in centigrade. Mothers/care givers were interviewed using a structured questionnaire to assess the knowledge and practices of newborn warmth care.

Demographic details like age, religion, literacy, socioeconomic status, and other details like antenatal, perinatal history of mothers, knowledge and practices of warmth care were recorded using a predesigned proforma. ThermoSpots were procured from maternova.net by selffunding. ThermoSpot was applied to the axillary region of the newborn at one hour of life after recording the initial temperature by digital thermometer and left in place until it falls off on its own. Caregivers were educated about ThermoSpot that a bright green face (Newborn temperature $36.5^{\circ} \mathrm{C}$ to $37.5^{\circ} \mathrm{C}$ ) is normal, a pale green face (temp $36^{\circ}$ to $36.4^{\circ} \mathrm{C}$ ) indicates cold stress, a red face (temp $35^{\circ} \mathrm{C}$ to $36^{\circ} \mathrm{C}$ ) indicates moderate hypothermia, a black face (temp $<35^{\circ} \mathrm{C}$ ) represents severe hypothermia and a blue face (temp $>39.0^{\circ} \mathrm{C}$ ) indicates fever.

During follow-up visits, a total of six temperature recordings were noted in the first 3 days, four in the first 24 hours and then at 48 hours and 72 hours of life. Any change in the colour of the ThermoSpot was also noted during the follow up visits and the mother educated. Every visit was utilised to reinforce the caregivers/mothers' knowledge on newborn warmth care and assess their level of understanding and implementation of warmth care practices.

Data analysis was done by Microsoft Excel and SPSS (version 20) software. Frequency and percentage distribution were used to analyse the socio-demographic variables and level of knowledge of mothers. The level of knowledge was then cross tabulated against the maternal variables of interest. Statistical analysis was done using Chi square test to compare dependent and explanatory variables.

\section{RESULTS}

Out of 108 mothers, majority were in 20-24 years age group. 7 (6.48\%) mothers were below 19 years, 72(66.67\%) were 20-24 years, $26(24.07 \%)$ were $25-29$ years and $3(2.78 \%)$ were 30 years and above.

Out of 108 mothers, $9(8.3 \%)$ were illiterate, $99(91.7 \%)$ were educated. 24(22.2\%) mothers received primary education, 48 (44.4\%) attended high school and 27(25\%) received inter/ higher education

According to modified Kuppuswamy scale, 8 mothers (7.4\%) belonged to class II, $35(32.4 \%)$ were in class III, $56(51.8 \%)$ were in class IV and $9(8.3 \%)$ belonged to class V. Majority of mothers belonged to class IV (Upper lower). In the present study, out of 108 mothers, $67(62.1 \%)$ belonged to nuclear family and $41(37.9 \%)$ belonged to joint family.

All the 108 mothers in the study attended antenatal clinic. $57.4 \%$ of the mothers were multiparous (57.4\%). Vaginal deliveries accounted for $62.1 \%$ while Caesarean section accounted for $37.9 \%$.The proportion of male to female deliveries was almost equal with male neonates accounting for $51.8 \%$ and female babies $48.2 \%$ giving a male to female ratio of $1: 1$.

\begin{tabular}{|c|c|c|c|c|c|}
\hline \multirow{2}{*}{ Variable } & & \multicolumn{3}{|c|}{ Drying and Wrapping Up } & \multirow{2}{*}{ p Value } \\
\hline & & Yes & No & Total & \\
\hline \multirow{4}{*}{ Age Group } & $<19$ & $6(85.7 \%)$ & $1(14.3 \%)$ & 7 & \multirow{4}{*}{0.690} \\
\hline & $20-24$ & $65(90.3 \%)$ & $7(9.7 \%)$ & 72 & \\
\hline & $25-29$ & $25(96.2 \%)$ & $1(3.8 \%)$ & 26 & \\
\hline & $>30$ & $3(100 \%)$ & 0 & 3 & \\
\hline \multirow{3}{*}{ Religion } & Hindu & $81(91 \%)$ & $8(9 \%)$ & 89 & \multirow{3}{*}{0.833} \\
\hline & Christian & $16(94.1 \%)$ & $1(5.9 \%)$ & 17 & \\
\hline & Muslim & $2(100 \%)$ & 0 & 2 & \\
\hline \multirow{2}{*}{ Type of Family } & Nuclear & $63(94 \%)$ & $4(6 \%)$ & 67 & \multirow{2}{*}{0.256} \\
\hline & Joint & $36(87.8 \%)$ & $5(12.2 \%)$ & 41 & \\
\hline \multirow{2}{*}{ Education } & Illiterate & $5(55.6 \%)$ & $4(44.4 \%)$ & 9 & \multirow{2}{*}{0.0001} \\
\hline & Literate & $94(94.9 \%)$ & $5(5.1 \%)$ & 99 & \\
\hline \multirow{3}{*}{ Socioeconomic Status } & II & $15(100 \%)$ & 0 & 15 & \multirow{3}{*}{0.152} \\
\hline & III & $34(97.1 \%)$ & $1(2.9 \%)$ & 35 & \\
\hline & IV & $44(89.8 \%)$ & $5(10.2 \%)$ & 49 & \\
\hline
\end{tabular}




\begin{tabular}{|c|c|c|c|c|c|}
\hline & $\mathrm{V}$ & $6(66.7 \%)$ & $3(33.3 \%)$ & 9 & \\
\hline \multirow{2}{*}{ Parity } & Primi & $37(80.4 \%)$ & $9(19.6 \%)$ & 46 & \multirow{2}{*}{0.0001} \\
\hline & Multi & $62(100 \%)$ & 0 & 62 & \\
\hline \multirow{2}{*}{$\begin{array}{l}\text { Mode of } \\
\text { Delivery }\end{array}$} & NVD & $61(91.1 \%)$ & $6(8.9 \%)$ & 67 & \multirow{2}{*}{0.936} \\
\hline & LSCS & $38(92.7 \%)$ & $3(7.3 \%)$ & 41 & \\
\hline
\end{tabular}

Literacy and multiparity of the mothers were found to have statistical significance $(\mathrm{p}<0.05)$ regarding the knowledge of drying the baby and wrapping with warm clothes whereas mothers of different age groups, religions, type of family, mode of delivery and socioeconomic status ( $\mathrm{p}>0.05)$ has no statistically significant association.

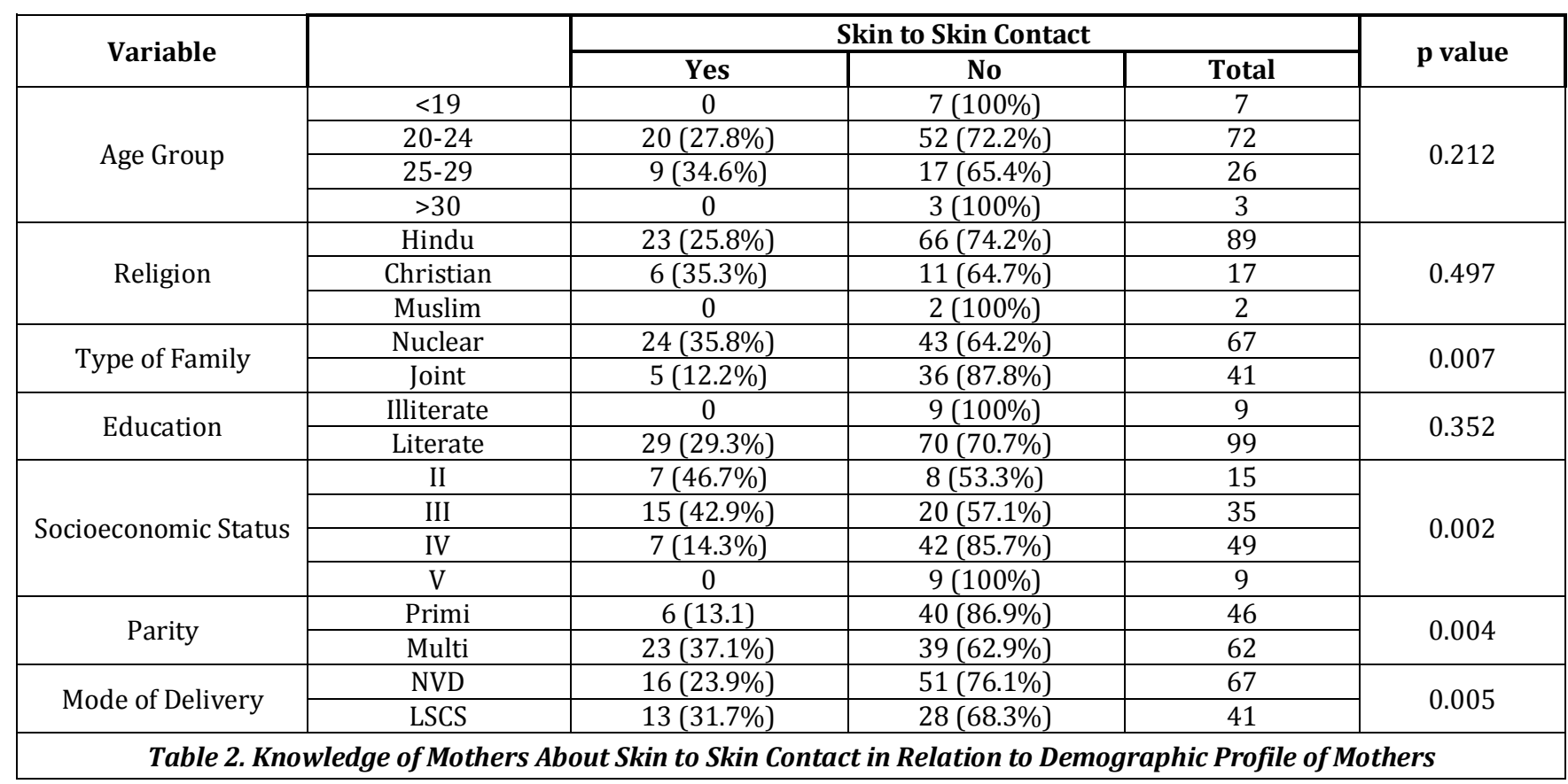

Mothers of nuclear family, higher socioeconomic status, higher parity and who had normal vaginal delivery had shown higher knowledge about skin to skin contact which was statistically significant $(\mathrm{p}<0.05)$ whereas knowledge about skin to skin contact had no statistical significance among mothers of different age groups, religion and educational status ( $\mathrm{p}>0.05)$.

\begin{tabular}{|c|c|c|c|c|c|}
\hline \multirow{2}{*}{ Variable } & & \multicolumn{3}{|c|}{ Rooming in } & \multirow{2}{*}{ p Value } \\
\hline & & Yes & No & Total & \\
\hline \multirow{4}{*}{ Age Group } & $<19$ & $2(28.6 \%)$ & $5(71.4 \%)$ & 7 & \multirow{4}{*}{0.001} \\
\hline & $20-24$ & $62(86.1 \%)$ & $10(13.9 \%)$ & 72 & \\
\hline & $25-29$ & $24(92.3 \%)$ & $2(7.7 \%)$ & 26 & \\
\hline & $>30$ & $3(100 \%)$ & 0 & 3 & \\
\hline \multirow{3}{*}{ Religion } & Hindu & $75(84.3 \%)$ & $14(15.7 \%)$ & 89 & \multirow{3}{*}{0.613} \\
\hline & Christian & $15(88.2 \%)$ & $2(11.8 \%)$ & 17 & \\
\hline & Muslim & $1(50 \%)$ & $1(50 \%)$ & 2 & \\
\hline \multirow{2}{*}{ Type of Family } & Nuclear & $62(92.5 \%)$ & $5(7.5 \%)$ & 67 & \multirow{2}{*}{0.007} \\
\hline & Joint & $29(70.7 \%)$ & $12(29.3 \%)$ & 41 & \\
\hline \multirow{2}{*}{ Education } & Illiterate & $3(33.3 \%)$ & $6(66.7 \%)$ & 9 & \multirow{2}{*}{0.0001} \\
\hline & Literate & $88(88.9 \%)$ & $11(11.1 \%)$ & 99 & \\
\hline \multirow{4}{*}{$\begin{array}{c}\text { Socioeconomic } \\
\text { Status }\end{array}$} & II & $15(100 \%)$ & 0 & 15 & \multirow{4}{*}{0.0001} \\
\hline & III & $35(100 \%)$ & 0 & 35 & \\
\hline & IV & $39(79.6 \%)$ & $10(20.4 \%)$ & 49 & \\
\hline & $\mathrm{V}$ & $2(22.2 \%)$ & $7(77.8 \%)$ & 9 & \\
\hline \multirow{2}{*}{ Parity } & Primi & $31(67.4 \%)$ & $15(32.6 \%)$ & 46 & \multirow{2}{*}{0.001} \\
\hline & Multi & $60(96.8 \%)$ & $2(3.2 \%)$ & 62 & \\
\hline \multirow{2}{*}{ Mode of Delivery } & NVD & $53(79.1 \%)$ & $14(20.9 \%)$ & 67 & \multirow{2}{*}{0.0001} \\
\hline & LSCS & $38(92.7 \%)$ & $3(7.3 \%)$ & 41 & \\
\hline
\end{tabular}

Knowledge about rooming in had shown statistically significant among educated mothers, mothers belonging to higher socioeconomic status, higher parity and who had normal vaginal delivery $(p<0.05)$ whereas it was statistically not significant among mothers of different age groups and religion $(\mathrm{p}<0.05)$. 


\begin{tabular}{|c|c|c|c|c|c|}
\hline \multirow{2}{*}{ Variable } & & \multicolumn{3}{|c|}{ First Bath-Immediately after Bath (Within 24 hrs.) } & \multirow{2}{*}{ p Value } \\
\hline & & Yes & No & Total & \\
\hline \multirow{4}{*}{ Age Group } & $<19$ & 0 & $7(100 \%)$ & 7 & \multirow{4}{*}{0.642} \\
\hline & $20-24$ & $10(13.9 \%)$ & $62(86.1 \%)$ & 72 & \\
\hline & $25-29$ & $4(15.4 \%)$ & $22(84.6 \%)$ & 26 & \\
\hline & $>30$ & 0 & $3(100 \%)$ & 3 & \\
\hline \multirow{3}{*}{ Religion } & Hindu & $9(10.1 \%)$ & $80(89.9 \%)$ & 89 & \multirow{3}{*}{0.081} \\
\hline & Christian & $5(29.4 \%)$ & $12(70.6 \%)$ & 17 & \\
\hline & Muslim & 0 & $2(100 \%)$ & 2 & \\
\hline \multirow{2}{*}{ Type of Family } & Nuclear & $11(16.4 \%)$ & $56(83.6 \%)$ & 67 & \multirow{2}{*}{0.172} \\
\hline & Joint & $3(7.3 \%)$ & $38(92.7 \%)$ & 41 & \\
\hline \multirow{2}{*}{ Education } & Illiterate & 0 & $9(100 \%)$ & 9 & \multirow{2}{*}{0.347} \\
\hline & Literate & $14(14.1 \%)$ & $85(85.9 \%)$ & 99 & \\
\hline \multirow{4}{*}{$\begin{array}{c}\text { Socioeconomic } \\
\text { Status }\end{array}$} & II & $2(13.3 \%)$ & $13(86.7 \%)$ & 15 & \multirow{4}{*}{0.056} \\
\hline & III & $7(20 \%)$ & $28(80 \%)$ & 35 & \\
\hline & IV & $4(8.2 \%)$ & $45(91.8 \%)$ & 49 & \\
\hline & $\mathrm{V}$ & $1(11.1 \%)$ & $8(88.9 \%)$ & 9 & \\
\hline \multirow{2}{*}{ Parity } & Primi & $6(3.1 \%)$ & $40(86.9 \%)$ & 46 & \multirow{2}{*}{0.541} \\
\hline & Multi & $8(12.9 \%)$ & $54(87.1 \%)$ & 62 & \\
\hline \multirow{2}{*}{ Mode of Delivery } & NVD & $8(11.9 \%)$ & $59(88.1 \%)$ & 67 & \multirow[t]{2}{*}{0.905} \\
\hline & LSCS & $6(14.6 \%)$ & $35(85.4 \%)$ & 41 & \\
\hline \multicolumn{6}{|c|}{ Table 4. Knowledge of Mothers About Timing of New-Born's First Bath in Relation to Demographic Profile of Mothers } \\
\hline
\end{tabular}

There was no statistical significance between knowledge of mothers about timing of new-born's first bath and demographic profile of mothers.

\begin{tabular}{|c|c|c|}
\hline Initiation of Breastfeeding after Delivery & Number of Mothers & Percentage (\%) \\
\hline Immediately & 86 & 79.6 \\
\hline On Demand When Baby Cries & 22 & 20.4 \\
\hline Total & 108 & 100 \\
\hline \multicolumn{2}{|c|}{ Table 5. Knowledge of Mothers About Early Initiation of Breastfeeding } \\
\hline
\end{tabular}

Out of 108 mothers, 86 (79.6\%) had knowledge to initiate breast feeds immediately after delivery where as $20.4 \%$ of mothers thought that breast feeds can be fed only when baby cries.

\begin{tabular}{|c|c|c|}
\hline Colour of ThermoSpot & Number of ThermoSpot Readings & Percentage \\
\hline Bright Green & 643 & 99.2 \\
\hline Pale Green & 4 & 0.6 \\
\hline Red & 1 & 0.2 \\
\hline Black & Zero & \\
\hline Blue & Zero & \\
\hline Total & 648 & 100 \\
\hline & Table 6. Colour of ThermoSpot & \\
\hline
\end{tabular}

Out of 648 (6 times from each baby) ThermoSpot readings, 4 ( 4 out of 648 readings $=0.6 \%$ ) mothers reported PALE GREEN once, and one mother reported RED colour once (1 out of 648 readings $=0.2 \%$ - moderate hypothermia). Majority of the ThermoSpot readings were normal and of bright green ( 643 out of 648 readings $=99.2 \%$ ). None of the babies had severe hypothermia/fever as black colour/blue colour of the ThermoSpot was not reported by any of the mother.

\section{DISCUSSION}

Neonatal hypothermia has been shown to increase neonatal mortality and morbidity. ${ }^{3,4}$ Warmth care is an essential component of newborn interventions to reduce neonatal mortality.

Newborn hypothermia is ubiquitous, including tropical environments. In the present study, the prevalence of hypothermia was low (3.7\%), which is on par with Kaushi k et al study (2.9\%). ${ }^{5}$ Other studies like Bolam et al (63\%), 6 
Johanson et al (85\%), ${ }^{7}$ Anderson et al (81\%), ${ }^{8}$ Nayeri and Nilli (53.3\%), ${ }^{9}$ Bang et al (17\%), ${ }^{10}$ Kumar and Aggarwal $(11.1 \%),{ }^{11}$ and Darms tadt et al $(45 \%)^{12}$ have shown higher prevalence of hypothermia.

Newborn must be carefully dried and covered with warm clean clothes to prevent heat loss through evaporation of the amniotic fluid.13,14 In the present study, almost $91.7 \%$ mothers had knowledge about drying and wrapping up the baby after delivery. Literate and multiparous had more knowledge than illiterate and primi mothers. This study is similar to the study by Padiyath $\mathrm{M}$ et al (77\%). ${ }^{15}$ Knowledge about tis warmth care practices was less in other studies like Iyengar SD et al (25.8\%), ${ }^{16}$ A. H. Baqui et al (14.1\%), ${ }^{17}$ Osrin D et al (4\%), ${ }^{18}$ Sri Ramareddy et al (13.8\%). ${ }^{19}$

Skin-to-skin care is defined as placing an infant prone clad, only in a nappy onto the caregiver's bare chest. It enhances breastfeeding success during the early postpartum period $^{13}$ and increases the duration of breastfeeding after discharge. ${ }^{14}$ In VLBW infants, it has been associated with improved weight gain ${ }^{20}$ and a reduction in mortality, severe infection and length of hospital stay compared with standard care.1,2 Moreover, STS care in newborns immediately after birth stabilises cardio-respiratory adaptation ${ }^{3}$ and decreases duration of infant crying. ${ }^{4}$ Knowledge of mothers about skin to skin contact was low (26.8\%) in the present study. In other studies like Padiyath $\mathrm{M}$ et al (India), Sinha et al (India), Sloan et al (Rural Bangladesh), the knowledge of mothers was $3 \%, 20 \%$ and $24 \%$ respectively. Mothers from higher socioeconomic status and nuclear families have shown better knowledge.

Babies born either at home or hospital should be kept with their mothers 24 hours a day in the same bed, in a warm room so that it is easier to keep the baby warm and breast feed on demand. In the present study, knowledge about rooming in was encouraging with majority of the mothers $(84.3 \%)$ having awareness about rooming in. It was high in educated, higher socio economic, multiparous mothers and also in those mothers who delivered vaginally. In other studies like Padiyath $\mathrm{M}$ et al, Hajela $\mathrm{S}$ et al, Rani $\mathrm{M}$ et al, and Begum J et al, the knowledge about rooming in was $84.3 \%$, $18 \%, 88 \%, 87.5 \%$ and $44 \%$ respectively

WHO recommends bathing after six hours of life and preferably on the second or third day of life. Blood, vernix and meconium will have been wiped off during initial drying at birth. Remaining vernix need not be removed as it is harmless and may reduce heat loss and is reabsorbed through skin during the first few days of life. The practice of bathing newborn immediately after birth in present study is $12.9 \%$. This is much lower compared to other Indian studies like Shreyash J Gandhi et al (37.8\%), A.H. Baqui et al (93.1\%), Sartaj Ahmad et al. (76.6\%), Nithin Kumar et al (71.7\%) and Padiyath $\mathrm{M}$ et al (24\%).

Breastfeeding is of benefit to both mother and the newborn. Immediate breast feeding stimulates uterine contraction and delivery of placenta in mother therefore preventing postpartum haemorrhage. For the newborn, early breastfeeding provides nutrition, warmth and colostrum with several immunological factors that prevent infections. ${ }^{13}$ Prelacteal feed is the feed given to newborn before initiation of breast feeding. This common cultural practice delays the initiation of breastfeeding and hampers the proper establishment and future successful breast feeding. It can also cause diarrhoea and electrolyte imbalance in the newborn. The custom of giving prelacteal feeds to baby is practiced even outside India, as observed in studies from Pakistan (35\%), Botswana (49\%) and China (26\%). In the present study, breast feeding knowledge was encouraging with as many as $79.6 \%$ of study population had the knowledge to initiate breast feeding immediately after delivery. Early initiation of breast feeding in other studies was less ranging from 5\% in A. H. Baqui et al, 57.9\% in Sreerama Reddy et al and $61.5 \%$ in Shankar Prasad et al.

\section{CONCLUSIONS}

In the present study, lack of maternal education on essential newborn care during antenatal (5\%) and postnatal periods $(13 \%)$ by health personnel was found to be one of the important factors contributing to poor knowledge and implementation of essential newborn warmth care practices. As majority of the mothers in the present study were literates and in the age group of 20-24 years, it is easy to bring about behavioural changes about implementation of healthy newborn care practices.

Most of the mothers were convinced about the need for practice of warmth care measures. But, as the customs and traditional beliefs are deep rooted and also because of compulsion from other family members, mothers (especially primigravida mothers) were unable to discard negative practices. Therefore, continuous reinforcement of the need for warmth care practices and other essential newborn care practices should be stressed at every opportunity by all the health care personnel involved in the care of newborn babies in the antenatal and postnatal visits. Usage of the simple and feasible devises like ThermoSpot device has been successfully tested in hospital and community settings (Kennedy et al, Kambarami et al, Green et al).

As ThermoSpot is not costly (Rs. 7 per device) and established to be useful to detect hypothermia, it can be incorporated in the neonatal kit supplied to health workers. Health workers can educate the mothers regarding its usage to detect hypothermia in the newborn. Simultaneously, they can utilise the opportunity to impart knowledge to mothers and caregivers regarding the adverse effects of harmful beliefs and cultural practices on newborn health and also highlight the importance of warmth care practices and other essential newborn care practices.

Poor dissemination of information regarding essential newborn care practices by health personnel in antenatal and post-natal period could be due to heavy work load and under staffing prevailing in the health facilities of most of developing countries.

Under NRHM, several incentive-based interventions were launched to promote maternal and newborn care. Essential newborn care practices are non-incentive based and the overburdened health staff are unable to spend much time on implementation of these newborn practices which is having an adverse influence on neonatal morbidity and mortality. Hence improving the staff pattern, working conditions and insistence on proper health education of mothers and caregivers by health workers on implementation of essential newborn care practice is of utmost importance to prevent hypothermia and promote intact survival of newborn babies. 


\section{REFERENCES}

[1] Trending of rates. SRS Statistical Report 2013. Registrar General of India.

[2] Manuel TA. Development indicators. 2014:1-84.

[3] Mullany LC. Neonatal hypothermia in low-resource settings. Semin Perinatol 2010;34(6):426-33.

[4] WHO. Thermal protection of the newborn: a practical guide. Maternal health and safe motherhood programme. Geneva: WHO 1997.

[5] Kaushik SL, Grover N, Parmar VR, et al. Hypothermia in newborns at Shimla. Indian Pediatr 1998;35(7):652-6.

[6] Bolam A, Manandhar DS, Shrestha P, et al. The effects of postnatal health education for mothers on infant care and family planning practices in Nepal: a randomized control trial. BMJ Clinical Research 1998;316(7134):805-11.

[7] Johanson RB, Malla DS, Tuladhar C, et al. A survey of technology and temperature control on a neonatal unit in Kathmandu, Nepal. J Trop Pediatr 1993;39(1):4-10.

[8] Anderson S, Shakya KN, Shrestha LN, et al. Hypoglycemia: a Common problem among uncomplicated newborn infants in Nepal. J Trop Pediatr 1993;39(5):273-7.

[9] Nayeri F, Nili F. Hypothermia at birth and its associated complications in newborn infants: a follow up study. Iran J Public Health 2006;35(1):48-52.

[10] Bang AT, Reddy HM, Deshmukh MD, et al. Neonatal and infant mortality in the ten years (1993 to 2003) of the Gadchiroli field trial: effect of home based neonatal care. J Perinatol 2005;25 Suppl 1:S92-107.

[11] Kumar R, Aggarwal AK. Body temperatures of home delivered newborns in north India. Trop Doct 1998;28(3):134-6.
[12] Darmstadt GL, Kumar V, Yadav R, et al. Community perceptions of birth weight in rural Uttar Pradesh, India: implications for care of low birth weight infants. J Perinatol 2008;28 Suppl 2:S53-60.

[13] Lawn JE, Cousens S, Zupan J. 4 million neonatal deaths: when? where? why? Lancet 2005;365(9462):891-900.

[14] Bryce J, Daelmans B, Dwivedi A, et al. Coundown to 2015 for maternal, newborn and child survival: the 2008 report on tracking coverage of interventions. Lancet 2008;371(9620):1247-58.

[15] Ekambaram M, Bhat VB, Ahamed MAP. Knowledge, attitude and practice of breastfeeding among postnatal mothers. Curr Pediatr Res 2010;14(2):11924.

[16] Iyengar SD, Bhakoo ON. Prevention of neonatal hypothermia in Himalayan villages: role of the domiciliary caretaker. Trop Geogr Med 1991;43(3):293-6.

[17] Baqui AH, Williams EK, Darmstadt GL et al. Newborn care in rural Uttar Pradesh. Indian J Pediatr 2007;74(3):241-7.

[18] Osrin D, Tumbahangphe KM, Shreshtha D, et al. Cross sectional, community based study of care of newborn infants in Nepal. BMJ 2002;325(7372):1063.

[19] Sreeramareddy CT, Joshi HS, Sreekumaran BV, et al. Home delivery and newborn care practices among urban women in western Nepal: a questionnaire survey. BMC Pregnancy Childbirth 2006;6(1):27.

[20] Senarath U, Fernando DN, Vimpani G, et al. Factors associated with maternal knowledge of newborn care among hospital-delivered mothers in Sri Lanka. Trans R Soc Trop Med Hyg 2007;101(8):823-30. 